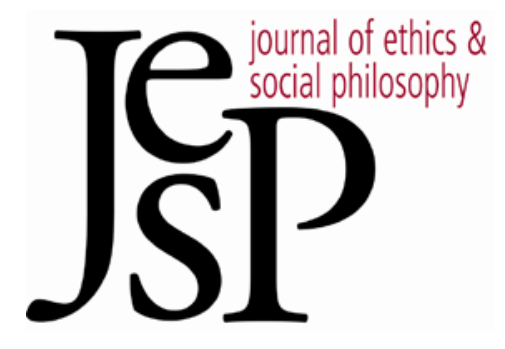

\title{
THE Significance OF a Duty's Direction:
}

\section{Claiming Priority Rather than Prioritizing Claims}

By MaRcus HEDAHL 


\title{
The Significance of a Duty's Direction: Claiming Priority Rather than Prioritizing Claims
}

\author{
Marcus Hedahl
}

O CAPTURE THE RICH COMPLEXITY of the moral domain, we
need to recognize not only that agents have duties, but that they often
owe directed duties to others. When Tom makes a promise to Mary, for example, he does not merely have a pro tanto duty to do as he promised; he has a duty to Mary to do so. As such, if Tom fails to keep his promise, he does not merely do wrong, he wrongs Mary. ${ }^{1}$ Additionally, Mary's concerns, at least defeasibly, ought to have more normative import with respect to Tom's duty than the concerns of other, uninvolved agents ought to have. ${ }^{2}$ Furthermore, Mary appears to have a "special standing" to demand that Tom fulfill his promise and to rebuke him if he fails to do so. ${ }^{3}$

Such considerations are hardly novel. In fact, with increasing frequency, failure to capture directionality itself is cited as a drawback of a given theory. One sees objections that an opposing framework cannot capture the fact that a given duty is to an animal, ${ }^{4}$ to those wronged by environmental malfeasance, ${ }^{5}$ to one's friend ${ }^{6}$ or to a promisee. 7 As I argue in more detail below, however, despite the increased consideration about its importance, existing attempts have all failed to capture the normative significance inherent in the directional nature of the duties we owe to others.

Historically, directionality has been analyzed in terms of claims and claim rights. Returning to our original simplistic example, if Tom has a duty to Mary, then Mary has a claim against Tom, the content of which is the same as the content of his corresponding duty. This point has been endorsed numerous times since W. N. Hohfeld first advanced it in 1919. Following Hohfeld's lead, the vast majority of theorists have folded the question of how to capture the nature of owing a directed duty to another into the question of how to capture the nature of a claim, for the two are taken to be analytic equivalents. ${ }^{8}$

\footnotetext{
1 This intuitive point is given an excellent philosophical analysis by Michael Thomson (2007) in "What Is It to Wrong Someone? A Puzzle About Justice." In particular, see 338-42.

2 This is a feature that some take to be central to considerations of rights. See, in particular, Ronald Dworkin (1984) "Rights as Trumps."

3 Joel Feinberg (1980) and Stephen Darwall (2006) take such standing to be an essential element of directed duties and claim rights. I will explicitly consider this possibility in section 2 .

${ }^{4}$ See, for example, Beauchamp (2011).

5 See, for example, Shrader-Frechette (2007).

6 See, for example, Jeske (2008).

7 See, for example, Tognazzini (2007) and Kolodny and Wallace (2003).

8 See, for example, Hohfeld (1919: 65-75); Thompson (2007: 335-32); Darwall (2012: 343 46).
} 
Recently, however, some have questioned the necessity of this connection. Some theorists have argued that directed duties need not entail claims. ${ }^{9}$ I might well owe it to a former student to write a letter of recommendation after she requests that I do so, owe it to a friend to help her move if she has helped me move in the past, and owe it to a kind stranger to express gratitude for her assistance - even though none has a claim against me. Alternatively, others have suggested that claim rights need not entail the existence of directed duties. ${ }^{10}$ The type of positive, basic human rights codified in the U.N. Charter, for instance, might capture claims we all possess, even before those claims become specifically addressed to particular agents, either individual or collective. Henry Richardson sums up this latter position nicely when he says, "It seems a mistake for a moral philosopher to let faithfulness to Hohfeld sideline human rights." 11

Against this backdrop, I propose to analyze directed duties themselves rather than the claims that may or may not universally correspond to such duties. ${ }^{12}$ Doing so, I contend, allows us to uncover novel difficulties with well-established theories of claim rights and to discover salient normative elements we might otherwise overlook. My hope is, nonetheless, that such an approach can serve as a next step to rather than a rejection of a Hohfeldinspired analysis.

To that end, I consider an important, though often overlooked, difference between directed duties and non-directed duties: the fact that counterparties can prioritize duties owed to them. Ultimately, I defend a novel account of directionality that locates the unifying element of directed duties in a counterparty's prioritization of the duties owed to her. ${ }^{13}$ To put the point broadly for the moment: If $\mathrm{B}$ has a directed duty to A to $\Phi$, then how much $\Phi$-ing matters to A, itself matters - in a distinctive, special and inherent sense. ${ }^{14}$ Ultimately, I argue that this intuitive notion, properly developed, forms the core concept at the heart of directed duties. The subjectdetermined element of directed duties can be used to delineate them from non-directional duties and it can demonstrate why many have taken control

\footnotetext{
${ }_{9}^{9}$ See, for example, Little and McNamara (2013).

10 See, for example, Ashford (2006) and Richardson (2012). Both take themselves to be building off the frameworks of Shue (1996) and, to a lesser extent, Pogge (2002).

11 Richardson (2013: 7).

12 I am not advocating that directionality and claims must be distinct. Rather, I contend the possibility that they might be gives us a reason to investigate directionality as a moral phenomenon that could be independent of claims. Even if it turns out that directed duties entail claims, claims entail directed duties or the two entail one other, I believe that an investigation focused solely on directed duties can shed new light on directionality as well as on the claims that, at the very least, often accompany such duties.

13 Throughout, I use the term "counterparty" to designate the entity to whom a directed duty is owed and "claimant" to designate one who has a claim.

14 As I will make more explicit below, "how much $\Phi$-ing matters to $A$ " is not reducible to some brute fact about A's interests. If $\mathrm{A}$ is an agent, A gets to decide, within proper constraints, how much $\Phi$-ing matters.
} 
JOURNAL OF ETHICS \& SOCIAL PHILOSOPHY | VOL. 7, NO. 3 THE SIGNIFICANCE OF A DUTY'S DIRECTION: CLAIMING PRIORITY RATHER THAN PRIORITIZING CLAIMS

powers, interests or the authority to demand compliance to be so important in analyzing one agent's duty to another.

\section{Interests and Powers}

In standard circumstances, one difference between a claimant and another member of the moral community lies in the interest each has in having duties fulfilled. An interest theory of claim rights builds off this distinction, holding that the puzzle of claims is best solved by equating claims with a claimant's significant interests. Perhaps the most prominent interest theorist is Joseph Raz, who contends:

$\mathrm{X}$ has a [claim] right iff $\mathrm{X}$ can have [claim] rights and, other things being equal, an aspect of X's well-being (his interest) is a sufficient reason for holding some other person(s) to be under a duty. ${ }^{15}$

Other interest theorists offer slightly different conditions. ${ }^{16}$ Details aside, however, in an interest theory, claimants are understood as the counterparts to duties that are grounded in a specific way, namely on claimants' interests (rather than on some authority a claimant possesses or on some particular deontological principle). According to an interest theory, claims are fundamentally linked to normative justifications. The interest theory thereby seeks to account for both why $\Phi$-ing is a duty and why $\Phi$-ing is a directed duty to another.

Shifting our attention more specifically to directed duties, an interest theory, as a theory of owing a directed duty to another, therefore holds:

An agent (B) has a duty to another agent (A) to $\Phi$ if and only if $A$ has some particularly strong type of interest that grounds B's duty to $\Phi$.

For example, if a cat's pain is the reason that kicking the cat is wrong, refraining from kicking it is thereby a duty owed to the cat. ${ }^{17}$ An interest theory as a theory of owing a duty to another thereby highlights a significant normative insight about directionality. In an important sense, we wrong the cat if we fail to regard its pain as a direct, reason-giving feature of the world. In that case,

15 Raz (1986: 166).

16 Other prominent interest theorists include MacCormick (1982) and Kramer (2001). Although some interest theorists appeal to the utilitarian tradition of Bentham and Mill, the two need not rise and fall together.

17 One could have an interest theory of directionality like Raz's interest theory of claim rights that further stipulates that the entity must be able to have duties owed to it. Perhaps cats could not meet that criterion. For those who may be skeptical, replace the example of a cat with one of an infant. The insight is similar even if more limited in its scope. 
we would fail to regard properly the normative significance of the cat and the limitations she places on our potential normative freedoms. ${ }^{18}$

As many have pointed out, however, accounting for claims via interests presents a difficulty with respect to third-party interests. ${ }^{19}$ Another agent, C, could have a greater interest in B's duty to A to $\Phi$, but that need not imply that $\mathrm{C}$ has a claim against B. Friends, family, and fans could have a greater interest in seeing that duties owed to others be fulfilled, but that fact need not transform them into further claimants. ${ }^{20}$

I believe that this well-known limitation of the interest theory as a theory of claims points to an even more foundational problem for an interest theory as a theory of directionality. Grounding directed duties via interests loses one of the most significant, distinctive elements of such duties: their relational and non-transitive nature. If $\mathrm{B}$ has a duty to $\mathrm{A}$ to $\Phi$, and $\mathrm{B}$ has a duty to $\mathrm{C}$ to $\Psi$, it need not be the case that $\mathrm{C}$ has a duty to A, even if C's $\Psi$-ing is required for B's $\Phi$-ing.

Imagine that I have promised to give my couch to Lauren to help furnish her new apartment. This duty remains a duty to Lauren even if another party has a significant - indeed, more significant - interest in my compliance. Even if Lauren conditionally promises her current, well-worn couch to Greg, who has no couch at all, her duty to Greg does not entail my duty to Greg. However, it would be difficult for an interest theory, as a theory of directionality, not to adopt a closure rule in these kinds of cases. I have a duty that must be fulfilled in order for Lauren to be able to fulfill her duty, and Lauren's duty is grounded, in part, on Greg's significant interests. I would violate a duty if I did not give my couch to Lauren, and it would be a violation, in large part, because of the impact on Greg's interests.

The interest theory's conclusion that my duty to Lauren engenders a further duty to Greg is problematic because it loses the important relational aspect of directed duties. The duty bearer and the counterparty are linked by the duty the former has to the latter. ${ }^{21}$ Tom owes it to Mary to keep his promise, and I owe my couch to Lauren. Owing a duty to another (as opposed to simply having a duty) is fundamentally a relational normative phenomenon. As the example above illustrates, however, there are times when an interest theory, as a theory of directionality, will not be able to account for that foundational feature.

18 One can violate a deontic principle by failing to regard something in the normatively appropriate manner. An interest theory as a theory of directionality leads us to the conclusion that these types of deontic principles can be directional in nature. One can do wrong by failing to regard something appropriately, and one can wrong another by doing so.

19 See Hart (1955: 81), Sreenivasan (2005: 262) and Wenar (2005: 232) for a more detailed consideration of the objection that third-party interests demonstrate that the interest theory is too exclusive, i.e., it mistakenly categories some non-claimants as claimants.

${ }^{20}$ See Kramer and Steiner (2007: 284-87) for one response to this objection against the interest theory as a theory of claims.

${ }^{21}$ Sreenivasan (2010: 467); Thomson (2004: 338). 
Fortunately, interests are not the only normatively significant element involved in directed duties. The second major theory to consider is the will theory. Once again, in the literature, the will theory is most developed as a theory of claims; so we begin our considerations of the will theory as a theory of claims. The view begins with the notion that, inarguably, claimants often possess some normative powers simply by virtue of being claimants. Given the normative importance of these powers, one might believe that they provide the best way to capture the significance of claims. A will theory of claims does just that. H. L. A. Hart, perhaps the most prominent will theorist, contended that possessing a claim is equivalent to possessing three powers:

(i) the power to waive X's duty or not

(ii) the power to enforce X's duty or not, given that X has breached it

(iii) the power to waive X's duty to compensate. ${ }^{22}$

Particular will theorists may disagree about whether a claimant must possess the full set of such powers. ${ }^{23}$ Details aside, however, a will theory, as a theory of claims, reduces claims to clearly enumerated, normatively significant powers, such as the power to waive and the power to enforce. If $\mathrm{A}$ has the power to control B's duty to $\Phi$ in some important way, then A has a claim against B that $\mathrm{B} \Phi$.

Importantly, will theories differ from interest theories not only in their justificatory grounding, but also in their intended purpose. A will theory's intended function is more modest: to explicate how the existence of a claim alters the moral landscape in ways that the existence of a mere duty does not. More specifically, the will theory focuses on how claims alter normative authority, where such authority is analyzed as the standing to maintain or eliminate a pro tanto duty. Unlike an interest theory, a will theory does not attempt to explain why a claimant is a claimant; for will theorists, having such authorities and being a claimant are simply analytic equivalents.

Shifting our attention specifically to directed duties, a will theory, as a theory of owing a directed duty to another, therefore holds:

An agent (B) has a duty to another agent (A) to $\Phi$ if and only if $A$ has some set of normative control over B's duty to $\Phi$.

A will theory, as a theory of directionality, thereby highlights another important insight about the nature of directionality. In order for an agent to make her life her own, she must have the ability to take on ends and prioritize some projects over others, an enterprise that would be aided by having the power to release some duties and enforce others.

22 Hart (1982: 183-84).

23 Other prominent will theorists include Wellman (1985) and Steiner (1994). Although some will theorists appeal to the Kantian tradition, the two need not rise and fall together. 
Unfortunately, the will theory, like the interest theory, has significant limitations not only as a theory of claims, but also as a theory of directionality. The will theory appears to have difficulty grounding inalienable claims and directed duties that cannot be waived, because the will theory contends that $\mathrm{B}$ owes a duty to $\mathrm{A}$ if and only if $\mathrm{A}$ has some measure of control over B's duty, but there appear to be some duties B has to A that do not correspond to any control power of A. The duty of B to respect A, as well as $\mathrm{B}$ 's duty not to enslave, torture, or kill $\mathrm{A}$, all seem to be duties that $\mathrm{B}$ has to $A$ that A cannot waive.

This problem points to a more foundational issue with equating directed duties with authority-based ones. Even if a counterparty alienates herself from all counterparty authority, doing so would not imply that she is no longer owed the successful completion of another's duties. Even though incompetent counterparties lack any authority, for instance, it should be uncontroversial to point out that one can wrong and not merely harm infants, the infirmed and, many will argue, certain nonhuman animals, by not fulfilling the duties regarding them (e.g., by assaulting them). ${ }^{24}$

The analysis in this section is not intended to provide knockdown criticisms of the will or interest theories as theories of claims. Rather, I contend that once we construe the will and interest theories more specifically as theories of owing a duty to another rather than as theories of claims and claim rights, we will find them wanting in terms of their ability to capture the intuitive, inherently relational aspect of those directed duties. Although a satisfactory theory of directionality ought to explain the powers to waive and enforce and the link between directed duties and interests, it ought to do so without abandoning the relational, non-transitive nature of directed duties. Regardless of their success as a foundation for a theory of claims, neither normative control powers nor interests can ground the normative significance of the directed duties we have to others.

\section{Demands and Complaints}

The reductionist analysis of claims by the will and interest theories has left many wanting. Some of those who find these theories unsatisfying have focused their attention on another important aspect of directed duties: a prereflective intuition that a counterparty has "special standing" to demand compliance for the duties owed to her and to complain when those duties have been violated. Those theorists who focus on this significant element of

24 See MacCormick (1982: 154-66), McCormick (1977: 195), Wenar (2005: 230) and Sreenivasan (2005: 231) for a more detailed consideration of the objection that inalienable claims and incompetent parties demonstrate that the will theory is too exclusive, i.e. it mistakenly categorizes some claimants as non-claimants. 
directionality - sometimes labeled "demand theorists" 25 - attempt to highlight an important element that is lost when directed duties are reduced to a counterparty's interests or normative powers.

According to these theorists, after a duty has been violated, a counterparty possesses "a privileged authority to complain or object ... not shared by mere observers." 26 Additionally, counterparties have "a distinctive discretionary second-personal authority" to legitimately demand that duties owed to them be fulfilled. ${ }^{27}$ In fact, according to these theorists, it is the possibility of "claiming" directed duties that gives these duties their special significance. ${ }^{28}$ According to Darwall, "failure to account for this distinctive secondpersonal aspect will miss an essential element" of the directed duties we owe to one another. ${ }^{29}$

Darwall may well be right on this last point, but unfortunately, without further analysis, any "distinctive discretionary second-personal authority" or "privileged basis for complaint" lacks the requisite content to delineate counterparties from third parties.30 Counterparties may possess some type of normative authority above and beyond the power to waive and enforce, but they lack the type of constitutive authority typically possessed by military officers and government officials. To return to our original example, Mary cannot establish Tom's duty to help her. He already has that duty, and it was created not by Mary's authority, but rather by his promise to her.

Equally problematic is the following: Since, at times at least, third parties can legitimately demand that duties be fulfilled and complain that they have not been fulfilled, one must guard against the possibility of losing any distinguishing feature about how directed duties are duties owed to counterparties. 31 Intuitively, there is a difference between counterparties, who have the authority to demand as their due, and third parties who can demand that the morally required action be performed. Darwall captures the force of this intuitive distinction nicely when he says, "each person has a distinctive set of individual authorities over others' conduct with respect to his feet that he doesn't have with respect to the treatment of other people's feet." 32 However, the difference cannot be merely the power to waive one's claim against having others stand on one's feet, lest the demand theory risks collapse into a will theory; and leaving it as a merely intuitive distinction cannot do the work required to delineate counterparties from the rest of the moral community. Some further

25 This is a term used by Wenar (2011). I will follow the use of the term in this section, but as may become clear by the end of the paper, it is less clear to me that these theorists offer a reductionist view of claims the way will and interest theorists do.

26 Wallace (2007: 29).

27 Darwall (2012: 350).

${ }^{28}$ Feinberg (1980: 155).

${ }^{29}$ Darwall (2012: 350).

${ }^{30} \operatorname{Raz}(2010: 292)$.

31 Raz (2010: 286).

32 Darwall (2012: 348). 
analytic delineation would be required between a counterparty's demanding as her due and a third party's demanding that morally required action be performed. ${ }^{33}$

Even if these issues could be resolved, however, a more foundational problem remains for linking directionality with the authority to demand compliance: The authority to licitly demand that another $\Phi$ requires $\Phi$-ing to be an all-things-considered duty, but a directed duty to $\Phi$ merely indicates the presence of a pro tanto duty. To demonstrate, one only needs to consider a basic case of conflicting directed duties, such as a parent who has promised identical items to both of her children. Then, "it turns out to his horror that he is able to locate only one." 34 It cannot be the case, all things considered, that the parent ought to fulfill both duties, because he is unable to do so. Further, the parent's directed duty to one child can be overridden by other more pressing moral considerations, such as equal consideration. ${ }^{35}$ B's directed duty to A to $\Phi$ does not imply that in all possible circumstances, B ought to $\Phi .{ }^{36}$ No directed duty provides a conclusive all-things-considered ought; these duties are, by their very nature, pro tanto. ${ }^{37}$

Yet counterparty status, and some specific kind of authority, remains, even when other ethical considerations outweigh the corresponding duty. In such cases, there is generally some other, lesser duty owed to a counterparty, such as the duty to notify. ${ }^{38}$ Furthermore, even if a duty is outweighed, a counterparty can still be due reparations for the failure to fulfill that duty. Nonetheless, in these situations, the concept of demanding seems oddly out of place.

While there may be a pro tanto equivalent of licit all-things-considered demanding, such as "urging what one is due," "pressing the importance of one's due" or "pressing one's claim," 39 these findings put pressure on the viability of trying to link directionality with the authority to demand or complain at any level. Since there are cases in which an agent has a duty owed to her but cannot licitly or aptly demand that it be fulfilled, being a counterparty to a directed duty cannot be equivalent to having the authority to all-thingsconsidered demand. Replacing "the authority to demand" with "the authority to press one's claim" cannot solve this problem. To do so would link being a counterparty to a directed duty with possessing the distinctive authority to press the claim that corresponds to that duty. Without some further analysis

33 I will discuss this distinction in greater detail in section 5.

34 Thompson (1990: 82).

35 There may be cases in which directed duties conflict with other considerations of justice (Griffin 2008: 64). Perhaps in some particular manifestations of this more general case, a parent could have certain duties of equality that would dictate that she should choose not to fulfill either duty, rather than fulfilling only one of them (e.g., perhaps a parent should not give the promised item to either child if the children are unable to share the item peacefully).

36 Sreenivasan (2010: 469).

37 Thompson (1990: 80-86); Sreenivasan (2010: 257-74).

38 For a more detailed consideration of the duty to notify, see Alonso (2009: 455-65).

39 This is a move that Darwall has made in informal dialogue. 
JOURNAL OF ETHICS \& SOCIAL PHILOSOPHY | VOL. 7, NO. 3 THE SIGNIFICANCE OF A DUTY'S DIRECTION: CLAIMING PRIORITY RATHER THAN PRIORITIZING CLAIMS

Marcus Hedahl

about the content of that authority, such a move risks becoming circular, vacuous, or both. 40

\section{Prioritization: From an Intuitive Notion to a Philosophical Concep- tion}

Let us therefore return to the original issue. The duty bearer and the counterparty are linked by the duty the former has to the latter. ${ }^{41}$ Tom owes it to Mary to keep his promise, I owe my couch to Lauren, and we owe it to the cat not to kick it. In this section, I consider an important, though often overlooked, difference between directed duties and non-directed duties: the fact that counterparties can prioritize duties owed to them. I then use this intuitive notion to develop a more rigorous, philosophic account of priority, one that distinguishes between de facto prioritization and de jure prioritization.

Let us start, however, with an extremely simple case. Ted makes two separate promises to Yamilee. He first promises to proofread her metaphysics paper by August 1, and then promises to proofread her ethics paper by August 1. Unfortunately, on July 30, Ted realizes, much to his ethical chagrin, he could proofread one but not both by the deadline. So, the obvious question becomes, what should Ted do? The equally obvious answer is that, after apologizing for his inability to meet both promises, Ted should determine how Yamilee would prioritize the duties owed to her. ${ }^{42}$ To flip a coin or to consult his own preferences would fail to respect that these are directed duties owed to Yamilee. If Ted cannot meet both duties, then Yamilee should be the one who decides which one ought to be fulfilled.43

Staying with this simple case, it is easy to see why Yamilee is the one to prioritize these duties. An uncontroversial aspect of promising is that, in standard circumstances, a promise involves the transfer of moral freedom. ${ }^{44}$ Agents sometimes are accorded the moral freedom to favor their own projects over an action that would bring about a greater increase in aggregate, net utility.45 A general feature of promises, however, is the transfer of such

40 Although I do not take a priority account to be a demand theory, I believe that the rest of the paper provides a possible further analysis of the authority to demand as one's due.

${ }^{41}$ See Sreenivasan (2010: 467) and Thomson (2004: 338).

42 In standard cases, Ted would ask Yamilee what she would prioritize. However, prioritization is not fundamentally about discursive or deliberative duties (c.f. Harel and Yuval 2012). If Yamilee has already provided a prioritization, Ted need not seek her out.

${ }^{43}$ Notice that Ted cannot settle the issues by noting that he would rather proofread the ethics paper or by noting that Yamilee's friend Wilma would rather he proofread the ethics paper. There is something normatively significant in this case about Yamilee's prioritization.

44 This contention is meant to be a general one about the way an agent's promise changes her subsequent moral freedom; I do not intend to advance nor to rely upon any particular analysis of the fundamental normative element involved in promising. A change in normative freedom need only be a usual consequence of promising, it need not be the essential element of promising.

45 See, for example, Williams (1973). 
freedom to another. ${ }^{46}$ In this case, if Ted had not promised Yamilee, he would have had the moral freedom to choose to proofread her papers or not to do so. Likewise, in the absence of a promise, if Ted could proofread only one, he would have the moral freedom to choose which one. Since he promised to proofread both papers, however, he no longer has the moral freedom to refrain from reading either. Moreover, if he can read only one, he similarly lacks the ability to freely choose between them. The normative authority to prioritize between $\Phi$-ing and $\Psi$-ing is simply a subset of the normative authority to choose to $\Phi$ and to choose to $\Psi$. If only one duty can be fulfilled, then, unless other moral considerations are involved, the counterparty's prioritization must merit deference. In this case, Yamilee can prioritize the duties owed to her.

To unpack and formalize this intuitive notion, let me begin by distinguishing two different kinds of prioritization. The first is de facto prioritization, a prioritization of duties due to a counterparty set by certain objective facts about her interests. Imagine that Ted cannot consult Yamilee about which duty to fulfill because she is out of reach. Fortunately, he has available an epistemically reliable guide that can tell him which duty's compliance would actually be in Yamilee's best interests. Her interests, we might say, provide a prioritization. This de facto prioritization is not anything effected by Yamilee; it is, instead, a prioritization about her.

The second is a very different notion - de jure prioritization. De jure prioritization is an exercise of a counterparty's authority to designate which duties she deems more significant. De jure prioritization is something a counterparty does. A counterparty might consult her own best interests, designating the duty that would best satisfy them. However, she need not do so. For instance, Yamilee might direct Ted to favor her ethics paper because proofreading it will take less time, and she wants to be nice to him. In other words, a counterparty may defer a duty due to her for all sorts of reasons having to do not with her own interests, but rather with other normatively significant features. A counterparty can defer a duty due to her even if those reasons do not override the duty owed to her. Alternatively, if Ted previously had demonstrated a blatant disregard for the directionality of duties he owed to Yamilee - telling her, for instance, "I'm doing what I promised, but you have nothing to do with it" - then Yamilee could direct him to prioritize a certain paper because doing so serves a pedagogical, developmental purpose. ${ }^{47} \mathrm{De}$ jure prioritization need not be a mere reporting of a de facto interest.

In the absence of any further communication from Yamilee, Ted ought to follow the de facto prioritization set by her interest. We might thus say

${ }^{46}$ See, for example, Watson (2009: 160-65).

${ }^{47}$ I also believe that agential counterparties, such as Yamilee, can take on ends, an activity that can change the prioritization the agents otherwise might provide. While these new ends, once adopted fully, can be captured once again by a de facto prioritization, exercising the ability to provide a de jure prioritization likely will be required when one is in the process of taking on new ends. 
that Yamilee's de facto prioritization provides the default. A de jure prioritization from an agential counterparty, however, would trump the de facto prioritization set by her interests. At least at times, a counterparty can decide for herself which duties she deems more important.

Significantly, de jure prioritization is not an instantiation of the power to waive. Two features of this case demonstrate that Yamilee's prioritization does not release Ted from either of the duties he owes to her. First, although Ted may no longer be able to proofread the non-prioritized paper by August 1, Yamilee could still demand that he do so shortly thereafter. Yet she could not demand that he do so if she had waived one of her claims, because she lacks the authority to reconstitute Ted's corresponding duty. She cannot unilaterally make Ted duty bound to proofread either of the papers; he has those duties because he promised. If Yamilee were waiving a claim, Ted would not be duty bound to read the non-prioritized paper unless he made another, further promise to do so. Second, responsibility for the non-prioritized duty remains. Counterparties can hold agents responsible for their failure to perform one duty even after another has been prioritized. In this case, Yamilee could hold Ted responsible for his failure to proofread both papers before August 1. Such holdings would be nonsensical, however, if Yamilee had waived a claim and thereby removed a corresponding duty. Instead, Yamilee has exercised her de jure authority to prioritize the duties due to her, a fundamentally different activity. All pro tanto duties remain; the counterparty has merely determined their relative importance by prioritizing them.

I want to argue that both forms of prioritization play important constitutive roles in determining the strength of duties, a feature that will manifest itself differently in different situations. ${ }^{48}$ Sometimes that change in strength will alter the all-things-considered deontic status of a given action; prioritization can thus make an action that would be morally permissible, morally impermissible. In standard circumstances, for example, Yamilee's prioritization of her ethics paper makes Ted's proofreading her metaphysics paper instead an all-things-considered wrong. Other times, prioritization can change the strength of a given duty and thereby change other normatively significant elements. For example, changing the deontic strength of a duty can alter the way in which a duty ought to be fulfilled or the due care a duty bearer must take. Finally, changing the deontic strength of a duty could increase or decrease the moral residue of not fulfilling a given duty. Even if a counterparty's prioritization could not possibly change the all-things-considered appropriate course of action, it can amplify the moral residue of not fulfilling that duty, and thereby increase the moral repair that may be required after that pro tanto duty goes unfulfilled.

The constitutive role prioritizing plays in determining the strength of duties is perhaps easiest to see with de jure prioritization, since de jure prioritization is a type of normative authority. Significantly, however, de jure priori-

48 I am grateful to discussions with Maggie Little on this distinction. 
tization is not a type of normative authority merely because its exercise can change the all-things-considered appropriate course of action. There are, after all, numerous ways to alter what another agent ought to do, many of which are not related to any kind of authority. One agent could change what another all things considered ought to do by throwing a small child in a pool. However, even if one agent's poolside mischief makes it the case that another now has a duty to aid in that child's rescue, such a change is not properly considered an exercise of authority. ${ }^{49}$ This behavior does not affect the relevant duties themselves but rather the external circumstances that establish or trigger them. Because of this distinction, standard analyses of normative authority typically center on an agent's power to impose new pro tanto duties and to release existing pro tanto duties..$^{50}$

Yet creating and eliminating duties is not the only way to alter them. As any good manager in a modern office is aware, the authority to create new pro tanto duties is meaningless without the authority to prioritize existing ones. If a worker in a bureaucracy has more assignments than she can complete in a set period of time (a rather common occurrence), then having the authority to add new tasks to that list is not a useful authority unless the tasks will garner a certain normative importance. As my former commanding officer often would say, "I have no issue with others believing they can give you orders, so long as they recognize that I get to prioritize them." Further demonstration of the significance of this authority can be seen from the following exchange from NBC's television program, The Office:

Dwight: Michael has authorized ... an emergency anti-flashing task force.

Jim: Question: Won't that interfere with your other task forces?

Dwight: Answer: No, because this is being given priority one (Stupnitsky and Eisenberg 2007).

De jure prioritization is a type of normative authority because the counterparty is directly altering the deontic strength of duties themselves, rather than the external circumstances regarding those duties.

Similarly, de facto prioritization also can alter the deontic strength of a given duty. Even if a counterparty does not exercise any authority, she still has a special impact on the strength of duties owed to her. In the absence of the exercise of the de jure authority to prioritize, her de facto interests will prioritize the duties owed to a counterparty. However, this distinction does not diminish the directional nature of these duties, because what is normatively significant to a counterparty often will diverge from what is normatively significant from an impartial point of view.

Of course, a counterparty's prioritization will not be the only relevant feature that plays a role in determining the strength of a given pro tanto duty. The duty not to insult another, for example, is generally less significant than

${ }^{49}$ Thanks to Henry Richardson for this vivid example.

${ }^{50}$ See, for example, Raz (2010: 290-95). 
the duty not to kill another. If an agent happened to be placed in the unfortunate circumstance in which she would have to violate one of these duties, she should choose, almost universally, to violate the duty not to insult. ${ }^{51}$ Counterparties do not have the ability to set the deontic priority at any level. There are constraints on the extent to which a counterparty can impact the strength of duties owed to her.52 So long as A has any control over the strength of B's duty to $\Phi$, however, she maintains an important authority above and beyond the power to remind that $\Phi$-ing is a duty, and above and beyond the power to waive her claim.

The impact of a counterparty's prioritization is perhaps best understood within its constraints. External circumstances of all sorts - aggregate utility, others' rights and competing obligations - will set a range of deontic strength for a given duty.53 A counterparty's de facto interests will set a default strength within that range. An agential counterparty, by determining how significant fulfilment of the duty is to her, can exercise her de jure authority to prioritize, thereby modifying that default setting, once again, within a given range. ${ }^{54}$ If we picture a duty as a vector, then a counterparty's prioritization plays some role in determining its magnitude. External factors set the upper and lower limits, and the counterparty's prioritization sets a more precise magnitude within that range. 55

Picturing duties as vectors surely will be a limitedly useful metaphor, but it can help us see why this significant element of normativity is overlooked so often: The element of significance provided by the counterparty often may seem inconsequential when compared to more objective elements. When Luke is walking down the street, the disparate importance to an Epicurean and a Stoic of not being assaulted ought not even enter into his considerations when deciding how to treat them. ${ }^{56}$ Such questions have no place. After all, "a duty is a duty." This expression highlights an important feature of the moral domain, but it does not imply, of course, that all duties are equal in their force any more than the fact that "a debt is a debt" implies that all debts

${ }^{51}$ I do not mean to imply that this is the only other element that will be important for determining the deontic weight of a given duty. There will be numerous others, including the aggregate consequences of fulfilling one duty or another.

52 Therefore, one need not worry that prioritization gives counterparties too much authority over duty bearers. The counterparty can only modify the strength of a duty within a given range. In standard circumstances, for example, a counterparty cannot make another's duty to return a book more significant than the duty not to assault.

${ }^{53}$ In other words, the range is set by all objective factors other than a counterparty's interests.

${ }^{54} \mathrm{I}$ defend this relationship between de facto and de jure prioritization in more detail in the following section.

55 The breadth of the range set by objective features likely will vary based on a number of factors. In most circumstances, the more central a duty is to a counterparty's ability to make her life her own, the greater that range will likely be.

${ }^{56}$ Or, if you prefer, in standard circumstances, Luke's duty not to assault another will not appear to be impacted by whether the potential victim has more classically Epicurean beliefs or more classically Stoic beliefs about the harms involved. 
are equal in their magnitude. In the unlikely event that Luke had to assault one of the two individuals to save the lives of 20 , the significance to the counterparties (a significance that was always present) now becomes extremely salient. If he cannot consult either party's de jure prioritization, then Luke ought to pick the Stoic, if Stoic she genuinely is, because Luke's duty to refrain from assaulting a genuine Stoic matters less to her. ${ }^{57}$

To belay any fears that linking counterparty significance and deontic strength would turn the Stoics into the punching bags of the world and the Epicureans into the new utility hogs, we should note that additional, nondirectional duties can become relevant to the all-things-considered judgment as well. ${ }^{58}$ If Luke were to find himself in a dystopian reality where he was placed repeatedly in the unfortunate circumstance of having to punch one in order to save 20 , at some point the non-directional duties of justice and fairness would dictate that the appropriate all-things-considered judgment would be to pick the Epicurean. Nonetheless, we would be well served to keep allthings-considered judgments distinct from determinations about the strength of pro tanto duties owed to others..$^{5}$

The contention that a counterparty's prioritization plays a role in determining the deontic strength of a directed duty owed to her is, of course, radically different from the position that others can play a role in determining the deontic strength of a directed duty. A given action could have a greater allthings-considered normative importance precisely because of how significant the action is to a third party. However, it would be a premature oversimplification to believe that third-party importance plays the same role as a counterparty's prioritization. As I will attempt to demonstrate in the sections that follow, counterparty prioritizations (whether de facto or de jure) play a controlling role in setting the strength of a duty to $\Phi$. At the all-thingsconsidered level, the reasons linked to counterparty prioritizations can have an exclusionary force that the third-party considerations lack. ${ }^{60}$ In other

57 Once again, if you prefer, Luke ought to assault the individual with more classically Stoic beliefs about harm.

58 The framework in section 5 can be used to demonstrate that these duties are non-directed duties. Until that framework can be provided, it seems prudent simply to grant the intuition that these duties are non-directed duties.

59 It follows from this analysis that while it would be a greater all-things-considered wrong to assault the Stoic for the $n$th time, we cannot assume that the duty owed to her is stronger. I would ask any who are skeptical about this contention to postpone any objection until I have had a chance to consider the limits of de jure authority to prioritize at the end of section 4 .

${ }^{60} \mathrm{I}$ do not intend for this distinction to depend upon any particular metaethical view about how reasons interact at the all-things-considered level. Anyone who is skeptical that reasons can have this type of exclusionary structure can interpret the claim to be that "the importance of $\Phi$-ing to a counterparty will be multiplied at the all-things-considered level in a way the importance of $\Phi$-ing to a third party is not." Regardless of the metaethical framework in which the distinction between counterparties and third party is presented, the support for that distinction can be found in the special significance afforded a counterparty's prioritization among similar duties owed to them. I will provide more support for this contention in the following section. 
words, there will be some circumstances in which the importance of $\Phi$-ing to any given third party will be silenced at the all-things-considered level, but there is never a situation in which $\Phi$-ing remains a directed duty to a counterparty yet that counterparty's prioritization is silenced. We should strive to maintain a distinction between counterparties who have some dominion over at least some of the duties owed to them and third parties - even third parties who are severely impacted by certain duties.

So, to summarize the findings so far, the significance to a counterparty of a given pro tanto duty plays a constitutive role in determining the strength of that duty. Any counterparty lacking the ability to take on ends or to exercise a transactional authority to prioritize will have the duties due to her prioritized by her de facto interests. Finally, at least at times, agential counterparties can exercise a legitimate de jure authority to prioritize. In those cases, an agential counterparty can decide for herself which duties are most important to her. Such de jure authority to prioritize is not a subset of the power to waive, but it is, nonetheless, a normative authority because its exercise directly alters the deontic strength of duties themselves, rather than the external circumstances regarding those duties.

\section{The Relationship Between De Jure and De Facto Prioritizations}

The previous section considered the most basic case: A counterparty can prioritize among similar, voluntarily undertaken duties owed by a single counterparty. For ease of illustration, I used the example of two duties created by promises in order to demonstrate that an agential counterparty can, at least at times, exercise a de jure authority to prioritize contrary to the default de facto prioritization set by her interests. In this section, I argue more explicitly that the de jure authority to prioritize is not limited to cases involving the conflict of voluntarily undertaken duties or waivable duties. An agential counterparty can always exercise a de jure authority to prioritize and thereby modify the strength of the directed duties owed to her.

To do so, it will be helpful to consider another case, a variant of Bernard Williams' famous example of Jim and Pedro. ${ }^{61}$ After a recent spate of protests, Pedro wants to demonstrate the dangers of such "revolutionary measures." 62 He has, therefore, randomly selected one townsperson - let's call her Tabitha - for potential execution. However, since Pedro wants to demonstrate the government's ability to be merciful, he will roll a standard six-sided die. If the die lands on an even number, Pedro will kill Tabitha, but if the die lands on an odd number, he will spare her. At the last minute, however, Pedro notices Jim. Since Jim is considered an honored visitor, Pedro offers him the opportunity to participate. If Jim accepts Pedro's offer, Jim

61 Williams (1973: 98).

62 Ibid. 
will have to kill Tabitha only if the die lands on unlucky number four; otherwise she will be spared.63

Let us start the analysis of this case with the intuition that both Jim and Pedro have a directed duty to Tabitha not to kill her. ${ }^{64}$ I contend that the key to regarding Tabitha as a counterparty to Jim and Pedro's duties is that Tabitha's determination of the relative importance of their various compliance is constitutively relevant to the moral import of those duties. Tabitha's determination may not settle the question of what Jim all-things-considered ought to do, but it matters nonetheless in a critical way - and may even have the potential to alter what the all-things-considered appropriate course of action for Jim would be.

To understand my contention that Tabitha's determination is constitutively relevant to the moral import of the duties owed to her, consider how the case would play out differently depending upon Tabitha's communications with Jim. Consider first an iteration in which Tabitha implores Jim not to accept Pedro's offer. Although in his original case Williams takes the prisoners' preference for Jim's participation to be "obvious," surely with some imagination and a denial of a Hobbesian worldview, we can conceive of a number of reasons why a prisoner might want Jim to decline. ${ }^{55}$ Tabitha might believe that Jim's participation would make a revolution less likely, she might believe that Jim's complicity would validate the atrocities of the government, or she might believe that Jim's actions would change the very meaning of her death. All of these possibilities involve a different rank ordering of priorities, an arrangement that may not be immediately evident to someone who would prioritize differently.

If, however, Tabitha were to state that she would freely choose a higher chance of death at Pedro's hand than a lower chance of death at Jim's hand, then Jim's participation, if it can be justified at all, must now be justified by favoring some other prioritization of duties (perhaps his own, perhaps the prioritization of other townspeople, perhaps an objective prioritization Tabi-

${ }^{63}$ To keep the number of possibilities limited, we can also assume that Pedro has indicated that if Jim agrees to participate, rolls a four, but does not kill Tabitha, then Pedro will kill all the townspeople.

${ }^{64}$ This intuition can be justified as a starting point, at least in part, by the fact that if either man were to kill Tabitha he would not simply do something wrong, he would wrong her. The intention of the following analysis is to justify that intuition, to demonstrate that Jim and Pedro both owe it to Tabitha not to kill her. Even if I am successful in demonstrating this fact, however, that conclusion does not imply that the directed duties owed to Tabitha are the only relevant duties in question. Some theorists hold that the deontic wrong of killing cannot be captured fully by the directed duty to Tabitha not to kill her. Although I do not defend the contention here, I share the belief that there are also non-directional duties not to kill. However, I do not believe anything in the following analysis hangs on whether such a non-directed duty also exists.

65 Williams (1973: 99). 
tha rationally ought to make) ${ }^{66}$ over the prioritization Tabitha actually provided. In effect, Jim must be able to justify why he acted in spite of Tabitha's determination.

In the alternative scenario, Tabitha could ask Jim to go ahead and participate. Christine Korsgaard imagines a similar scenario as one in which the prisoner says, "Go ahead, participate - I forgive you." ${ }_{67}$ The choice of words in Korsgaard's analysis is significant - and telling. Notice the prisoner does not say, "I consent," a declaration that might seem more befitting. After all, the prisoner is trying to absolve Jim of his potential complicity, and consent has the potential to change the moral appropriateness of that action, rather than merely absolving him of a future wrong. The specifics of this case, however, may indicate why this more straightforward approach is problematic: Tabitha's claim against being killed might well be inalienable, in which case her attempts to consent would be futile. If Tabitha cannot waive her claim against Jim not to be killed, then she also cannot consent to his participation.

On the other hand, Tabitha is not merely indicating that she will forgive Jim, nor does she bind herself to some future forgiveness. "Go ahead" is as important to this exchange as is "I forgive you." Taken together, they suggest that the prisoner is attempting to constate some change in the normative status of Jim's action, rather than trying to indicate that repair would be possible if he were to wrong her. Taken literally, the declaration of prospective forgiveness suggests that even with Tabitha's consent, Jim's participation would nonetheless need forgiving, and that his participation is something that Tabitha berself could forgive. ${ }^{68}$ This possibility, however, would imply that Tabitha could make an action more deontically appropriate even though that action could still be pro tanto wrong and, more significantly, even though that action would still violate a duty due to her. But how can we make sense of that?

I contend that we can do so by understanding the broad scope of the de jure authority to prioritize. ${ }^{69}$ As we saw previously, an agent can rank duties without waiving any of them. This possibility implies that Tabitha can rank the relative importance of Pedro's duty and Jim's duty without waiving either. In this way, she can exercise a de jure authority, making Jim's violation of a pro tanto duty owed to her more or less deontically appropriate, even if Jim's duty corresponds to an inalienable claim. When Tabitha says, "Go ahead, participate - I forgive you," Jim's participation still may involve the violation

\footnotetext{
${ }^{66}$ The contrast between the role of counterparties' prioritizations (in this case, Tabitha's determination) and third-party prioritizations (in this case, anyone else's determination) in cases such as these seems to support the contention in the previous section that counterparty prioritizations play a controlling role in setting the strength of a duty to $\Phi$, whereas the importance of $\Phi$-ing to a third party has the potential to create a new, ancillary reason for action.

${ }^{67}$ Korsgaard (1996: 296).

${ }^{68} \mathrm{I}$ am thankful to the referees at the Journal of Ethics and Social Philosophy for their comments on this issue.

${ }_{69}$ There may well be other ways to make sense of this possibility.
} 
of a directed duty, but the violated directed duty is one that the counterparty herself has expressed to be less significant than the alternative possibility, a situation that also involves the violation of a duty owed to her.

As a result, regardless of how the all-things-considered judgments turn out, it would be more deontically appropriate for Jim to participate after Tabitha says, "Go ahead, participate - I forgive you," and less deontically appropriate for him to participate after she demands that he refrain. In these cases, Jim can wrong Tabitha not merely by violating a duty due to her; he can further wrong her by acting contrary to her expressed prioritization of the duties owed to her. He can wrong her by disrespecting her ability to decide for herself what matters most to her and her way of life. This finding is significant, for it implies that even duties that correspond to inalienable claims have certain nuanced normative authorities embedded within them: They are still susceptible to prioritization among similar duties.

In fact, the scope of a counterparty's de jure authority to prioritize is broader still. The significance of de jure prioritization is perhaps easiest to discern in cases in which two similar duties are owed to the same counterparty. In that case, a counterparty can increase the strength of one duty and decrease the strength of another, thereby making the strength of the former greater than the strength of the latter. Nonetheless, a counterparty can always prioritize a duty owed to her, even if she is owed only one, because the de jure authority to prioritize is exercised on singular duties rather than on sets of duties.

To demonstrate, consider our modified case of Jim and Pedro again, but this time, from Jim's point of view. While Tabitha is prioritizing two claims that correspond to two duties owed to her, from Jim's point of view, Tabitha is determining the significance of his singular duty owed to her. With the notable exception of the epistemic uncertainty regarding Pedro's actions, from Jim's point of view, the case would be no different if Pedro were replaced by causal forces. If Tabitha would stand a 50 percent chance of survival without Jim's intervention and a 16.66 percent chance of survival with Jim's intervention, once again, Tabitha's determination of how significant Jim's intervention is to her will play an important role in determining the significance of Jim's duty, even if Tabitha's claims against Jim were inalienable.

We could also consider a case in which an agent owed two different duties to two different counterparties that could not both be fulfilled. In that case, the relative de facto significance to each counterparty of fulfilling the only duty owed to her could influence, in many cases alter, which duty ultimately ought to be fulfilled. Similarly, one agent's de jure deference could also influence the decision about which duty ultimately ought to be fulfilled. These are not, however, cases in which a counterparty ranks two duties relative to each other, but rather cases in which a duty's importance is ranked relative to some objective, qualitative scale. Numerous other examples apply: returning a book, respecting another's beliefs, or meeting a deadline. The sig- 
nificance to the counterparty of the fulfillment of a particular duty owed to her will influence the strength of the duty itself.

Importantly, an agential counterparty need not merely report on the objective significance of these actions to her interests; she also can exerciese her de jure authority to prioritize. Since the duty is owed to her, this determination can increase (or decrease) the moral significance of fulfilling that particular duty.70 Agential counterparties always have some de jure authority to prioritize contrary to the de facto prioritization set by their interests. Respect for the agency of agential counterparties requires some deference for the prioritizations they actually make, rather than the prioritizations that, in a certain sense, they rationally ought to make. ${ }^{71}$ In other words, as Rawls puts it, "it is clearly left to the agent himself to decide what it is that he most wants and to judge the comparative importance of his several ends." 72 An agential counterparty can exercise the de jure authority to lower the normative strength of a duty owed to her without waiving that duty. ${ }^{73}$ Alternatively, an agential counterparty can exercise the de jure authority to raise the normative strength of a duty owed to her within a range set by external, objective circumstances. In other words, a counterparty's subjective assessment of the significance of fulfilling this particular duty always requires some deference. ${ }^{74}$

Of course, the fact that a counterparty's subjective assessment always warrants some deference does not imply that it warrants total deference. The de jure authority to prioritize is not absolute. Generally, one should not respect the wishes of a counterparty that says that a contingent, trivial duty owed to her ought to be treated as more important than a duty that corresponds to one of her inalienable claims. Cases of this kind do not demonstrate that an agential counterparty sometimes lacks a de jure authority to prioritize or that de facto significance sometimes trumps de jure prioritization. Rather, in these types of cases, we once again encounter the limits of prioritization previously considered. A counterparty can exercise her de jure authority to increase the deontic strength of the contingent, trivial duty, and she can exercise her de jure authority to decrease the deontic strength of the duty that corresponds to one of her inalienable claims. In some circumstances, however, she simply may lack the authority to make the contingent, trivial

70 This contention does not deny the principle that practical deliberation is about relative weights of options rather than absolute weights, for often counterfactual prioritizations (e.g., "Suzy would care more about returning this book than similar books" or "Bobby cares much more about returning the book on time than Steve would in similar circumstances") can help determine the relative importance of a given pro tanto duty in a given situation.

71 The lessons of the previous section are important to remember. First, the element of significance provided by the counterparty often may seem rather inconsequential when compared to more objective elements. Furthermore, external, objective circumstances will set a range of deontic strength for a given duty.

72 Rawls (1999: 366).

${ }^{73}$ One can think of this as a type of scalar waiving. A counterparty can lower the strength of a duty without waiving it.

74 Once again this deference is within a given range set by objective circumstances. 
duty strong enough and the duty owed to her that corresponds to one of her inalienable claims weak enough that the proper course of action is to fulfill the former duty rather than the latter. These types of cases need not trouble us here, however. If a counterparty's subjective determination has any weight at all, we have uncovered an important normative element of the directed duties one owes to another; such subjective determinations need not be universally decisive.

A counterparty is, therefore, the locus of prioritization for duties owed to her. In the absence of any exercise of de jure transactional authority, a counterparty's interests prioritize the duties owed to her. In other words, de facto prioritization sets the default prioritization. In the presence of an exercise of de jure transactional authority from a competent agential counterparty, however, that de jure prioritization takes precedence, even when it is in opposition to the counterparty's interests. ${ }^{75}$ Agential counterparties can, to some degree, modify the de facto prioritization set by their interests. This ability does not imply that, in every case, one ought to fulfill a duty that a counterparty has given a high prioritization. Like all pro tanto duties, the duty that a counterparty prioritizes could be outweighed by other ethical considerations. Nonetheless, since a counterparty's prioritization plays an important constitutive role in determining the strength of duties owed to her, she maintains an important authority over those duties.

\section{A Priority Account of Directionality}

The previous two sections have advanced several new considerations regarding directed duties, including a defense of a novel, significant counterparty authority: the de jure authority to prioritize. Although one could endorse some or all of these findings as independent, isolated features of directed duties, I believe they point to a central, unifying feature of the duties we owe to others. In this section, I argue that the constitutive role that a counterparty's prioritization plays in setting the relative strength of directed duty can be used to delineate directed duties from non-directed duties. I then demonstrate how this delineation can support a priority account of directionality, an account that can unify many of the insights of the will, interest, and demand theories.

As noted earlier, traditional theories of claims differ, not only in their theoretical grounding, but also in their intended purpose. Given the goal to

75 This point assumes that the prioritization in question is within the acceptable range set by objective factors. As with any authority, one could unsuccessfully attempt to exercise it when one does not have it. One can unsuccessfully try to waive an inalienable claim (e.g., trying to enter into a contract to sell oneself into slavery); similarly, one can unsuccessfully try to set a prioritization outside of the permissive range set by objective factors (e.g., trying to tell someone that her duty to return your book is more important than her duty not to kill another). For those interested in one way of resolving these underdressed and important issues at a more general level, see Harel and Yuval (2013). 
develop an account of owing a directed duty to another, it seems prudent, at least as a necessary first step, to consider the more modest goal of the will theory. ${ }^{76}$ An account of directionality ought to explain how the existence of a directed duty alters the moral landscape in ways the existence of a nondirected duty does not. ${ }^{77}$ While this primary task requires delineating directed duties from non-directed duties, it is fundamentally explanatory rather than analytical in nature. An account of directionality ought to be able to explain why directionality matters, i.e., it ought to explicate the normative complications created by the fact that a given duty is owed to another. This implies that an account of directionality ought to capture an aspect of the directed duty to $\Phi$ that other duties and other reasons for action lack. Additionally, an account of directionality ought to account for the significant elements of directionality already identified. In short, an account of directionality ought to be able to explain the powers of waiving and enforcing, to capture the link between directed duties and interests, and to provide some positive analysis about the way in which directed duties are inherently and irreducibly second personal.

Let us begin, however, with the question of delineation. As argued previously, directionality matters, at least in part, because counterparties can prioritize duties owed to them, and this prioritization will alter the strength of those duties. Oversimplifying a bit, this means that if B has a directed duty to A to $\Phi$, how much $\Phi$-ing matters to A, matters. More precisely, if B has a directed duty to A to $\Phi$, A's prioritization of $\Phi$-ing plays a controlling role in determining the strength of B's duty to $\Phi$. Therefore, directed duties contain a core, subject-determined element that is constitutive to the structure of the duty itself: the priority for A of B's $\Phi$-ing. This difference can help identify when directed duties exist:

B has a directed duty to A to $\Phi$ iff B has a duty to $\Phi$ and A's prioritization of $\Phi$-ing plays a controlling role in determining the normative strength of B's duty to $\Phi$.

In other words, the significance to A of B's $\Phi$-ing, whether the significance to $A$ is a substantive de facto significance or a purely formal de jure significance, is intrinsically relevant to determining the strength of B's duty.

With this distinguishing feature of directed duties in hand, we can articulate a priority account of directionality. The unifying, normatively significant element of a directed duty is the controlling role prioritization plays in determining the duty's strength. A directed duties is properly considered owed to

${ }^{76}$ If the reason A has a duty to $\Phi$ turns out to be the same as the reason that A's duty to $\Phi$ is a directed duty to $\mathrm{B}$, so much the better. But it would seem to be a mistake at this point simply to assume that the answers to these two questions must be linked in this way.

77 However, I do not intend to follow the will theory's exclusive focus on how directed duties alter normative authority. 
another because the counterparty's prioritization plays a controlling role in influencing its deontic strength.

A priority account of directionality thereby is not a will theory. While a claimant can refrain from exercising a normative control power, a counterparty cannot refrain from being the locus of a constitutively relevant prioritizing function. If a counterparty does not exercise a de jure authority, the duties owed to her are still prioritized by her de facto interests. Counterparties always supply a de facto prioritization - even in those cases in which no one could exercise de jure authority on their behalf. ${ }^{78} \mathrm{~A}$ priority account thereby can capture the duties owed to incompetent counterparties in a way in which the will theory cannot. ${ }^{79}$ Finally, a priority account can capture the fact that an agent could possess the traditional control powers of waiving and enforcing without being the counterparty to that duty. 80

It turns out that a will theory, as a theory of directionality, conflates the categories of duties originating from a certain source and directed duties to another. Consider, for example, the duties involved with guarding prisoners of war. Let us stipulate that a lieutenant orders a private to stand watch over a set of prisoners. The immediate origin of the private's duty was the order given by the lieutenant, but that order's moral authority (whatever its military or legal authority might be) crucially depends upon its being reasonably calculated to ethically promote a nation's interests in prosecuting a just war. Even though the duty originates from the lieutenant, it is a directed duty owed to the nation and its people. This fact explains why, if the private faces a conflict between guarding some high-level operators and guarding mere conscripts, the default would be to guard the former rather than the latter (even if it were in the lieutenant's interests to guard the latter). The duty to guard the prisoners can be analyzed without reference to the lieutenant, even though she has the authority to remove the duty and give it to another soldier. Unless the lieutenant actually exercises that authority, however, the duty remains, and we can analyze its content and determine its deontic strength without reference to the significance of this duty for her.

78 The question of whether proxies for incompetent parties can exercise de jure authority to prioritize contrary to the counterparty's interests is an extremely interesting one. I suspect that these types of proxies can do so, but I remain agnostic about that possibility for the purposes of this paper.

79 One could try to augment a will theory by adding the contention that the duties due to incompetent parties are prioritized by their interests. One could have, in effect, deontology for agents and consequentialism for incompetent parties (Nozick 1974: 39). However, in addition to the theoretical problems of such a hybrid approach (see Kramer and Steiner 2007), equating duties due to agents with control powers, while equating duties due to incompetent parties with interests, would sever the similarities between some of the common duties we owe to both kinds of counterparties (e.g., the duty not to cause unnecessary pain, the duty not to assault, etc.).

${ }^{80}$ In effect, the will theory, as a theory of directionality, will have difficulty differentiating between a counterparty exercising authority on her own behalf and a proxy exercising that authority on behalf of another. 
It would be easy to confuse the fact that the lieutenant has near total authority over the private to interpret the nation's interests with the misguided belief that the duties created by the lieutenant's orders are directed duties to her. ${ }^{81}$ We would be better served, however, if we took the lieutenant to be acting as a proxy for duties owed to the nation and her people, because if the private finds herself in a position where she cannot obtain new orders, has no advance directive, and cannot determine a substituted judgment, all considerations about the lieutenant drop from the private's deliberation. The lieutenant's own interests do not matter in determining the import of this duty.

A priority account of directionality thereby has another advantage over a will theory: an inherent structural mechanism for distinguishing proxies from counterparties. If the agent whose de facto prioritization sets the default strength for a given duty also has the de jure authority to prioritize, and thereby alter, the strength of that duty, then she exercises those authorities as a counterparty. If, however, an agent has the de jure authority to prioritize, and thereby alter, the strength of a given duty whose default strength is set by the interests of another, then the former acts as a proxy for the latter. ${ }^{82}$ Although much more analysis would be required to determine when an agent can exercise de jure authority for another, that analysis is not required to characterize the phenomenon: Proxies exercise the de jure authority of another entity on behalf of that entity.

Nonetheless, even though de facto prioritization can help delineate counterparties from proxies, a priority account of directionality is not an interest theory. The de jure authority to prioritize - even against an agent's own interests - has lexical precedence over de facto prioritizations. Furthermore, the de jure authority to prioritize is not justified by its impact on a counterparty's interests. Owing a duty to another should not be reduced to de facto prioritizations alone.

It turns out that an interest theory, as a theory of directionality, goes astray because it conflates the categories of duties with respect to a given entity and directed duties to another. To see how, we can return to our previous example involving a lieutenant's order for a private to guard prisoners of war. Even if the lieutenant were to give the order to guard the prisoners because she believes doing so is in the prisoners' best interests (perhaps she believes that unless they are guarded closely, they will attempt to flee and almost surely perish in the attempt), the duty created by that order still is not a directed duty to the prisoners. Of course, the private does have numerous other duties to each of the prisoners. She cannot demean their humanity, assault them, tor-

${ }^{81}$ See, for example, Wenar (2013: 213-14).

82 Obviously, much more analysis would be required to determine when one could exercise these authorities for another. Nonetheless, this straightforward delineation between counterparties and proxies is an important one because there are situations in which the authority of proxies will be more limited than a counterparty's authority would be if she were acting for herself in the exact same circumstances. 
ture them, etc. In this case, however, even if the lieutenant has the authority to order what is, in fact, in the prisoners' best interests, she cannot constate a new directed duty to them. In other words, in standard circumstances, the prisoners can decline to have the lieutenant act as their proxy with respect to these particular interests. 83

However, even though it is not an interest theory, a priority account of directionality can capture a significant link between directed duties and interests. Interests always set the default de facto prioritization. The prioritization of duties owed to non-agential counterparties and agential counterparties who do not exercise any counterparty authority generally is captured by their de facto prioritization. Interests play an important role in the directed duties we owe to others, even if interests do not provide the ultimate foundation for those duties.

Furthermore, even though it is not a will theory, a priority account of directionality can explain the significance of the traditionally considered normative control powers. Earlier, I provided several reasons why the de jure authority to prioritize could not be considered a subset of the power to waive. However, the converse claim is not true: The traditional powers of waiving and enforcing can be demonstrated to be types of prioritizations. An agential counterparty can give a non-inalienable claim a priority so low that the relative deontic strength of the corresponding duty becomes zero. In other words, a counterparty can give a non-inalienable claim a priority below a threshold such that the claim is waived and the corresponding duty is removed. Alternatively, a counterparty can give a violated duty a priority high enough to initiate enforcement. ${ }^{84} \mathrm{~A}$ priority account of directionality thereby has the ability to unify the traditional powers of the will theory, demonstrating why many have taken control powers to be so essential for analyzing one agent's duty to another.

Finally, a priority account of directionality is not a demand theory, but it can highlight one salient difference between demanding as one's due done by counterparties and demanding that the right action be performed done by third parties. Demanding that a duty be fulfilled is a complex action, one that involves, at a minimum, holding other agents to their duties. ${ }^{85}$ The normative intricacies of such holdings are beyond the scope of this particular investigation, but such details are not required to highlight the fact that, while the licit normative demands of counterparties ought to track existing duties, they

\footnotetext{
83 I leave open the possibility that the lieutenant could have the authority to act as the prisoners' surrogate with respect to other interests.

${ }^{84}$ Enforcement of a given directed duty may require elements other than a counterparty's prioritization, but some action on behalf of the counterparty is a necessary condition for those other elements of enforcement to be initiated. Theorists as diverse as Hart and Darwall seem to have this element in mind when they discuss the unique power of counterparties regarding enforcement for violated directed duties (Hart 1982: 183-90; Darwall 2010: 260-67).

85 See McNamara (2011) for more analysis on this point.
} 
need not merely reflect the objective facts of what morality requires. ${ }^{86}$ When A demands as her due that B $\Phi$, A can do more than merely point out that $\Phi$ ing is a duty, and she can do more than merely hold B to the duty to $\Phi .{ }^{87} \mathrm{~A}$ can use the demanding interaction to communicate the significance for her of B's $\Phi$-ing. In other words, an agent's demanding as her due can be regarded as a significant step in expressing the importance to her of fulfilling this particular duty. While likely not the only element of a counterparty's demanding as her due, a counterparty's exercise of her de jure transactional authority to prioritize can still be a significant element of such second-personal exchanges, and it is one that can delineate a counterparty's demanding as her due from a third-party's demanding that the right action be performed.

\section{Conclusion}

A priority account of directionality can capture and justify many of the significant aspects of the will, interest, and demand theories while offering a distinctive solution to the puzzle of directionality. Counterparties who are also agents are not merely reporting what duties are most important to them; they can take on ends that will alter those interests, and they possess a transactional de jure authority to alter the strength of duties owed to them, even if exercising that authority is contrary to their own interests. A priority account captures an agent's ability to determine such priorities for herself.

Furthermore, a counterparty need not be an agent in order for the duties owed to her to be prioritized. The prioritization of duties due to an incompetent party simply collapses to the prioritization of her interests. This fact, however, does not diminish the normative significance of the directional nature of duties owed to non-agential counterparties, because what is normatively significant to a counterparty often will diverge from what is normatively significant from a purely objective point of view.

A priority account of directionality thereby can preserve constraints and an element of control, even in hard cases, even for inalienable claims, and even for the claims of incompetent parties. Furthermore, a priority account locates dominion for those constraints where it belongs: with those to whom duties are owed. In this messy and complex world, capturing the significance of owing a duty to another requires more than establishing an agent's ability to determine which duties she wants to release and which she wants to maintain, and more than a consideration of what is really in her best interests. The

86 Once again, one might well be mistaken about what the duty in question is and what it entails. This possibility itself raises interesting complexities that I do not consider here. For an analysis of such cases, see Harel and Yuval (2012).

${ }^{87}$ Demanding as one's due that another $\Phi$ can also involve clarifying that $\Phi$-ing is a duty, that $\Phi$-ing is a duty to the agent who is demanding and that the agent to whom the duty is owed has not waived the duty to $\Phi$. It could also involve, in some contexts, communicating the intention to enforce any duty of reparation if the duty is not fulfilled. Correspondence with Alec Walen has been helpful on this point. 
subject-determined normative significance of prioritization is, in fact, the essential element of the directed duties we owe to others. ${ }^{88}$

\author{
Marcus Hedahl \\ United States Naval Academy \\ Department of Leadership, Ethics, and Law \\ marcushedahl@gmail.com
}

${ }_{88}$ Thanks to Maggie Little, Henry Richardson, Mark Lance, Bryce Huebner, Kyle Fruh, Kelly Heuer, Travis Rieder, and Tony Manela for their thoughtful and helpful considerations regarding the contents of this paper. 
JOURNAL OF ETHICS \& SOCIAL PHILOSOPHY | VOL. 7, NO. 3 THE SIGNIFICANCE OF A DUTY'S DIRECTION: CLAIMING PRIORITY RATHER THAN PRIORITIZING CLAIMS

\section{References}

Ashford, E. (2006) "Global Ethics: The Inadequacy of Our Traditional Conceptions of the Duties Imposed by Human Rights," Canadian Journal of Law and Jurisprudence 19: 217-35.

Beauchamp, T. (2011) "Rights Theory and Animal Rights," in T. Beauchamp and R. G. Frey, eds., The Oxford Handbook of Animal Ethics, Oxford: Oxford University Press, pp. 198-227.

Darwall. S. (2012) "Bi-Polar Obligation," in R. Shafer-Landau, ed., Oxford Studies in Metaethics, Vol. 7, Oxford: Oxford University Press, pp. 333-67. (2010) "Authority and Reasons: Exclusionary and Second Personal," Ethics 120(2): 257-78. (2006) The Second-Person Standpoint: Morality, Respect and Accountability. Cambridge, Mass.: Harvard University Press.

Dworkin, R. (1984) "Rights as Trumps," in J. Waldron, ed., Theories of Rights, Oxford: Oxford University Press, pp. 53-67.

Feinberg, J. (1980) Rights, Justice and the Bounds of Liberty, Princeton: Princeton University Press.

Graham, P. (1996) "The Will Theory of Rights: A Defence," Law and Philosophy 15(3): 257-70.

Griffin, J. (2008) On Human Rights, Oxford: Oxford University Press.

Harel, A. and Yuval, E. (forthcoming) "Rights and Deliberative Duties."

Hart, H. L. A. (1982) Essays on Bentham, Oxford: Clarendon Press. (1955) “Are There Any Natural Rights?” Philosophical Review 64: 175-91.

Hohfeld, W. N. (1919) Fundamental Legal Conceptions as Applied in Judicial Reasoning, New Haven: Yale University Press.

Jeske, D. (2008) Rationality and Moral Theory: How Intimacy Generates Reasons, New York: Routledge Press.

Kolodny, N. and Wallace, R. J. (2003) "Promises and Practices Revisited," Philosopby \& Public Affairs 31(2): 119-54.

Korsgaard, C. (1996) Creating the Kingdom of Ends, Cambridge: Cambridge University Press.

Kramer, M. (2001) "Getting Rights Right," in M. Kramer, ed., Rights, Wrongs and Responsibilities, London: Macmillan, pp. 28-95. and Steiner, H. (2007) "Theory of Rights: Is There a Third Way?” Oxford Journal of Legal Studies 27(2): 281-310.

Little, M. and McNamara, C. (forthcoming) "Between Obligatory and Optional."

MacCormick, D. N. (1982) Legal Right and Social Democracy, Oxford: Oxford University Press. (1977) "Rights in Legislation," in P. Hacker and J. Raz, eds., Law, Morality and Society, Oxford: Clarendon Press.

McNamara, C. (2011) "Holding Others Responsible," Philosophical Studies 152: 81-102.

Nozick, R. (1974) Anarchy, State and Utopia, New York: Basic Books. 
Pogge, T. (2002) World Poverty and Human Rights, Cambridge: Polity Press.

Raz, J. (2010) "On Respect, Authority and Neutrality: A Response," Ethics 120(2): 279-301. (1986) The Morality of Freedom, Oxford: Oxford University Press.

Richardson, H. (forthcoming) "Directing Rights: A Liability Theory."

Shrader-Frechette, K. (2007) "Human Rights and Duties to Alleviate Environmental Injustice: The Domestic Case," Journal of Human Rights 6: 10730.

Shue, H. (1996) Basic Rights: Subsistence, Affluence and U.S. Foreign Policy, Princeton: Princeton University Press.

Sreenivasan, G. (2010) "Duties and Their Direction," Ethics 120(3): 465-94. (2005) "A Hybrid Theory of Claim Rights," Oxford Journal of Legal Studies 25(2): 257-74.

Steiner, H. (1994) An Essay on Rights, Oxford: Blackwell.

Stupnitsky, G. and Eisenberg L. (2007) “Women's Appreciation,” The Office, $\mathrm{NBC}$, originally aired May 3.

Thomson, J. T. (1990) The Realm of Rights, Cambridge, Mass.: Harvard University Press.

Thomson, M. (2004) "What Is It to Wrong Someone? A Puzzle About Justice," in R. J. Wallace, P. Pettit, S. Scheffler and M. Smith, eds., Reason and Value: Themes from the Moral Philosophy of Joseph Raz, Oxford: Clarendon Press, pp. 333-84.

Tognazzini, N. (2007) "The Hybrid Nature of Promissory Obligations," Philosophy and Public Affairs 35(3): 203-32.

Wallace, R. J. (2007) "Reasons, Relations and Commands," Ethics 118: 24-36.

Watson, G. (2009). "Promises, Reasons and Normative Powers," in D. Sobel and S. Wall, eds., Reasons for Action, Cambridge: Cambridge University Press, pp. 155-78.

Wellman, C. (1985) A Theory of Rights, Totowa, NJ: Rowman \& Allanheld Press.

Wenar, L. (2011) "Rights," in E. Zalta, ed., Stanford Encyclopedia of Philosophy, fall 2011 edition, http://plato.stanford.edu/archives/fall2011/entries/ rights. (2008) "The Analysis of Rights," in M. Kramer, C. Grant, B. Colburn and A. Hatzistavrou, eds., The Legacy of H. L. A. Hart, Oxford: Oxford University Press, pp. 251-73. (2005) "The Nature of Rights," Philosophy and Public Affairs 33(3): 22352.

Williams, L. (1973) Utilitarianism: For and Against, Cambridge: Cambridge University Press. 